\title{
Gender differences in competitiveness and risk taking: comparing children in Colombia and Sweden ${ }^{*}$
}

\author{
Juan-Camilo Cárdenas ${ }^{\mathrm{a}}$, Anna Dreber ${ }^{\mathrm{b}},{\text { Emma von } \operatorname{Essen}^{\mathrm{c}} \text { \& Eva Ranehill }}^{\mathrm{d}}$
}

\author{
SSE/EFI Working Paper Series in Economics and Finance
}

No 730

June 2011

\begin{abstract}
We explore gender differences in preferences for competition and risk among children aged 912 in Colombia and Sweden, two countries differing in gender equality according to macro indices. We include four types of tasks that vary in gender stereotyping when looking at competitiveness: running, skipping rope, math and word search. We find that boys and girls are equally competitive in all tasks and all measures in Colombia. Unlike the consistent results in Colombia, the results in Sweden are mixed, with some indication of girls being more competitive than boys in some tasks in terms of performance change, whereas boys are more likely to choose to compete in general. Boys in both countries are more risk taking than girls, with a smaller gender gap in Sweden.
\end{abstract}

Keywords: competitiveness; risk preferences; children; gender differences; experiment. JEL codes: C91; D03; J16.

We are grateful for comments from Johan Almenberg, Thomas Buser, Alison Cool, Bart Golsteyn, Moshe Hoffman, Magnus Johannesson, Astri Muren, David G. Rand and seminar participants at ESA Copenhagen 2010, Gruter's Squaw Valley Retreat on Law, Institutions and Human Behavior 2010, Harvard Kennedy School, MOVE Workshop on Gender Differences in Competitiveness and Risk Taking, Stockholm School of Economics, and Stockholm University. We are especially grateful to Uri Gneezy for his encouragement to initiate this study as well as continuous feedback. Anna Dreber is grateful for support from Iris Bohnet and the Women and Public Policy Program at Harvard Kennedy School. The field work in Colombia could not have been completed without the help of Adriana Molina and Gloria Rodriguez and a number of volunteer students. Financial support from the Swedish Institute of Banking Research (Bankforskningsinsitutet) (A.D.), the Jan Wallander and Tom Hedelius Foundation and the Carl Silfvén Foundation (E.R.), the Swedish Council for Working Life and Social Research (FAS), and the Department of Economics at the Universidad de Los Andes is gratefully acknowledged.

a Economics, Universidad de los Andes, jccarden@uniandes.edu.co

b Institute for Financial Research (SIFR), anna.dreber@sifr.org

c Department of Economics, Stockholm University, emma.vonessen@ne.su.se

d Department of Economics, Stockholm School of Economics, Sweden, eva.ranehill@hhs.se 


\section{Introduction}

Men typically occupy the majority of top positions in most sectors in most societies, whereas women in many western countries are at least as likely as men to pursue higher education and to participate in the labor market. One possible and suggested cause of gender differences in labor market outcomes is that men and women differ in terms of economic preferences. In particular, preferences for competition and risk, where women in general are found to be less competitive and less risk taking than men (see, e.g., Croson and Gneezy 2009 for an overview), might contribute to explaining the labor market gender gap. Competitiveness is typically measured as either the performance response to a competitive setting compared to a non-competitive setting, or as a preference for competition such as self-selecting into a competitive setting instead of a non-competitive setting. However, relatively little is known about how the gender gap in economic preferences varies with age, and to what extent crosscountry differences in gender norms affect the gender gap. Studying children from different countries is one potential route to further this understanding.

In this paper we explore the gender gap in preferences for competition and risk among approximately 1200 children aged 9-12 in the two capitals Bogotá and Stockholm. Colombia and Sweden are two countries that differ in gender equality according to various macroeconomic indices (e.g., Hausmann et al. 2010). ${ }^{1}$ Our setup enables us to study to what extent there are systematic differences in the gender gap between Colombia and Sweden. We explore gender differences in competitiveness using four tasks: running, skipping rope, math and word search. These four tasks allow for the possibility that differences in gender stereotyping of the tasks influence the gender gap in competitiveness, i.e. there might be female and male areas of competition. We study competitiveness as the performance change between an individual setting and a forced competition in all four tasks, as well as the choice of whether to compete or not in math and word search. We also explore the gender gap in risk preferences by having the children choose between different incentivized lotteries.

There is some previous work on competitiveness and risk taking among children. In a field experiment on 9-10 year old children in Israel, Gneezy and Rustichini (2004a) find that boys react to competition by running faster against another child compared to an individual race, whereas girls do not change their performance. Contradictory to this finding, Dreber et al.

\footnotetext{
${ }^{1}$ In this report, Colombia ranks 55th and Sweden 4th in terms of gender equality according to this index. As far as we know, there are no studies comparing neither adult or children behavior in competitiveness and risk taking in Colombia and Sweden.
} 
(2011) find that 7-10 year old boys and girls in Sweden compete equally in running as well as in skipping rope and dancing. ${ }^{2}$ Moreover, Booth and Nolen (2009a) explore how the gender gap in choosing to compete among 15 year old adolescents in the UK depends on whether they go to a single sex or mixed school. Girls in single sex schools are more competitive than girls from mixed schools. Boys are found to be equally competitive in both types of schools, as well as more competitive than girls in both schools.

In parallel with this study, two other studies concerning gender differences in competitiveness among children have been conducted. Looking at running, Sutter and Rützler (2010) find that among 3-8 year old children in Austria, boys are more likely than girls to choose to compete. Sutter and Rützler also look at 9-18 year old children competing in math and find similar results to those on younger children, i.e. boys are more likely to choose to compete than girls. Moreover, Andersen et al. (2010) compare competitiveness, measured as the choice to compete when throwing tennis balls, among children aged 7-15 in a matrilineal society (the Khasi) and a patriarchal society (the Kharbi) in India. ${ }^{3}$ They find no significant gender difference in competitiveness in the matrilineal society, whereas in the patriarchal society a gender gap emerges in the age group 13-15, with boys being more competitive.

The type of competition task has also been shown to sometimes matter. Most of the literature focuses on math or maze tasks, tasks that are typically considered male, with a few exceptions. ${ }^{4}$ Two studies comparing the gender gap in competitiveness between a maze task and a word task find that the gender gap is influenced by the task (Grosse and Riener 2010, Günther et al. 2010) whereas another study finds no difference between these tasks (Wozniak et al. 2010). Gneezy and Rustichini (2004b) find that the gender gap decreases when adult subjects can choose to compete in solving anagrams compared to shooting baskets, whereas Dreber et al. (2011) find no gender gap in performance change in running, skipping rope or dancing among children.

Previous literature on the gender gap in risk taking among children shows mixed results. Booth and Nolen (2009b) look at single sex and mixed schools and find that boys are more risk taking than girls in mixed schools but that there is no gender gap when comparing boys to

\footnotetext{
${ }^{2}$ Dreber et al. (2011) find no impact of age on behavior. There are furthermore some differences between the setup of Gneezy and Rustichini (2004a) and that of Dreber et al. (2011).

${ }^{3}$ Matrilineal is a technical genealogical term, meaning that people trace descent through the mother's line. Patriarchal means that men have more power in society. These terms are not necessarily opposite: a society can for example be matrilineal (trace descent through the mother) and patriarchal (men have more power).

${ }^{4}$ The math task in this study is rated as being more boyish, see section $4 \mathrm{f}$.
} 
girls from single sex schools. Girls are also more risk taking when assigned to all-girl groups than when assigned to mixed groups. Borghans et al. (2009) find a gender gap among 15-16 year old children in the Netherlands, with boys being more risk taking than girls. ${ }^{5}$ However, unlike the latter two studies, Harbaugh et al. (2002) find no gender gap in risk taking among children aged 5-13 or among adolescents aged 14-20 in the US.

Moreover, evidence suggests that the gender gap in competitiveness and risk taking is influenced by the subject pool studied. Gneezy et al. (2009), in a study on adults, find that women compete more than men in a matrilineal society in India whereas the opposite is found in a patriarchal society in Tanzania. Moreover, the results of Booth and Nolen (2009a, 2009b), Andersen et al. (2010), and the differences between Gneezy and Rustichini (2004a), Dreber et al. (2011) and Sutter and Rützler (2010) also support the notion that the country or environment in which the study is performed matters. Since Colombia scores lower on gender equality indices than Sweden (Hausmann et al. 2010), we expect the gender gap to be bigger in Colombia in all four competition tasks as well as in risk taking compared to Sweden. We also expect the gender gap to be smaller (if there is any gap at all) in more feminine tasks such as skipping rope and word search compared to running and math in both countries.

We find little support for our hypotheses in Colombia, where boys and girls are equally competitive in all four tasks using both competitiveness measures. However, this is not the case in Sweden. Girls in Sweden increase their performance more than boys do when forced to compete in math, a traditionally male task, but there is also some indication of girls in Sweden being more competitive than boys in skipping rope, a traditionally female task. There is however no gender difference in reaction to competition in running or word search. Meanwhile, boys in Sweden choose to compete more than girls do when given the possibility. Boys and girls are thus consistently equally competitive in Colombia, whereas in Sweden boys are consistently more competitive in terms of choice and girls sometimes more competitive in terms of performance change. Our results suggest that tasks are only important for the gender gap in competitiveness in Sweden, but not in a uniform way. Risk taking, on the other hand, shows results in line with our expectations; the gender gap is larger in Colombia than in Sweden. With this little support for our hypotheses, however, we are agnostic to the specific variables that might drive our results.

\footnotetext{
${ }^{5}$ Borghans et al. (2009) also find that boys sometimes are more ambiguity averse than girls.
} 
The outline for our paper is the following. In section 2 we present the experimental setup. We give a summary of our hypotheses and results in section 3, and thereafter present these in more detail in section 4 . We finish with a discussion in section 5 .

\section{Experimental setup}

The study was divided into two parts: a physical education (PE) part and a classroom part. In the physical education part, the children competed in running and skipping rope, as well as participated in a cooperation task (the latter is described in Cárdenas et al. 2011). ${ }^{6}$ Running and skipping rope each consisted of two stages. In stage 1, the children performed the task individually. In stage 2 , the children performed the task in competition with another child. While performing the task in the first stage the children were unaware of the existence of a second stage. In the second stage, children were matched with someone who performed similarly to themselves in the first stage. If more than two children obtained the same result in stage one, the matching was random. The children were informed of the matching procedure. Performance in running was based on how fast the children ran $4 * 13$ meters. ${ }^{7}$ In the skipping rope task, the children jumped with a long rope that one teacher or experimenter and one child turned. Performance was measured by the number continuous of jumps. When competing in skipping rope, two ropes were put next to each other. The children were instructed to start jumping at the same time. Our measure of competitiveness during the physical education class is the absolute change in performance between the first and second stages, the most common measure of the reaction to competition. In the PE part, no compensation was awarded apart from the intrinsic motivation that comes from winning, as in Gneezy and Rustichini (2004a).

In the classroom, the children competed in math or word search, participated in a risk task and answered a survey. In each class, half of the children were randomly chosen to solve math exercises, whereas the other half were given a word search task. The children did not get any feedback about their performance in any stage. In the first stage, a piece-rate scheme, the children were told that they had two minutes to solve as many exercises as possible, for which they would be given 3 points each. In the second stage, a tournament, the children were again told that they would get two minutes to solve exercises, but that they now would be randomly paired with someone in the class who solved the same type of task, and that if they solved more or the same number of exercises as the other person, they would get 6 points per

\footnotetext{
${ }^{6}$ In the physical education part, children performed the tasks in the presence of their classmates.

${ }^{7}$ Since this study was conducted indoors we were constrained by the size of a regular PE class room.
} 
exercise, whereas if they solved fewer exercises than the other person they would get 0 points. In the third stage, the children were told that they were to solve exercises for another two minutes, and that they now could choose whether they wanted to be given points according to the piece-rate scheme or the tournament. Comparing performance in the second stage with performance in the first stage gives us a measure of competitiveness as absolute performance change or reaction to competition, whereas the choice in the third stage gives us a measure of competitiveness as a preference for competition. After the competitiveness task was over, we asked the children to guess how many children they believed had performed better than they had on the math task or the word task, for both the piece-rate scheme and the forced competition. This allows us to measure performance beliefs, or over- and underconfidence.

The risk task consisted of six choices where the children could choose between a lottery in the form of a coin flip that gives 10 or 0 points with equal probability, and a safe option where the certain amount increases successively (from 2 to 7.5 points). Our first measure of risk preferences relies on the unique switching point where the individual switches from preferring the lottery to preferring the safe option. Our main measure of risk preferences excludes inconsistent subjects, i.e. subjects with multiple switching points. Since some of our subjects are inconsistent we also analyze the number of times a person chooses the uncertain option compared to the safe option. This is our second measure of risk preferences. The results with these two measures are similar if not otherwise stated.

After the risk task, a survey was included in order to measure beliefs concerning the different tasks, cooperation and competition, as well as to measure demographics.

In the end of the classroom part, points were converted into pens and erasers. Before the study started, the children were told that more points corresponded to more pens and erasers.

We further use relative performance change as a robustness check in both the PE part and the class room part (see the Appendix for further explanation of the relative measure).

In sum, in this paper we analyze competitiveness as performance change in running, skipping rope, math and word search, competitiveness as choosing to compete or not in math and word search, and risk preferences through incentivized choices over lotteries and safe choices. We also look at additional measures such as overconfidence. 


\section{Summary of the results}

Table 1 provides an overview of our hypotheses and results. Surprisingly few of our hypotheses are supported. We discuss this more extensively in Section 4 and 5.

Table 1. Summary of results.

\begin{tabular}{|c|c|c|c|c|}
\hline Gender gap & Task & Hypothesis & Results & $\begin{array}{l}\text { Hypothesis } \\
\text { supported? }\end{array}$ \\
\hline \multirow[t]{10}{*}{ Colombia } & $\begin{array}{l}\text { Running - performance } \\
\text { change }\end{array}$ & $\mathrm{G}<\mathrm{B}$ & $\mathrm{G}=\mathrm{B}$ & No \\
\hline & $\begin{array}{l}\text { Skipping rope - performance } \\
\text { change }\end{array}$ & $\mathrm{G}<\mathrm{B}$ & $\mathrm{G}=\mathrm{B}$ & No \\
\hline & Gender gap between tasks & $\mathrm{R}>\mathrm{S}$ & $\mathrm{R}=\mathrm{S}$ & No \\
\hline & Math - performance change & $\mathrm{G}<\mathrm{B}$ & $\mathrm{G}=\mathrm{B}$ & No \\
\hline & Word - performance change & $\mathrm{G}<\mathrm{B}$ & $\mathrm{G}=\mathrm{B}$ & No \\
\hline & Gender gap between tasks & $\mathrm{M}>\mathrm{W}$ & $\mathrm{M}=\mathrm{W}$ & No \\
\hline & Math - choice & $\mathrm{G}<\mathrm{B}$ & $\mathrm{G}=\mathrm{B}$ & No \\
\hline & Word - choice & $\mathrm{G}<\mathrm{B}$ & $\mathrm{G}=\mathrm{B}$ & No \\
\hline & Gender gap between tasks & $\mathrm{M}>\mathrm{W}$ & $\mathrm{M}=\mathrm{W}$ & No \\
\hline & Risk & $\mathrm{G}<\mathrm{B}$ & $\mathrm{G}<\mathrm{B}$ & Yes \\
\hline \multirow[t]{10}{*}{ Sweden } & $\begin{array}{l}\text { Running - performance } \\
\text { change }\end{array}$ & $\mathrm{G}=\mathrm{B}$ & $\mathrm{G}=\mathrm{B}$ & Yes \\
\hline & $\begin{array}{l}\text { Skipping rope - performance } \\
\text { change }\end{array}$ & $\mathrm{G}=\mathrm{B}$ & $\mathrm{G}>\mathrm{B}$ & No \\
\hline & Gender gap between tasks & $\mathrm{R}=\mathrm{S}$ & $\mathrm{R}<\mathrm{S}$ & No \\
\hline & Math - performance change & $\mathrm{G}=\mathrm{B}$ & $\mathrm{G}>\mathrm{B}$ & No \\
\hline & Word - performance change & $\mathrm{G}=\mathrm{B}$ & $\mathrm{G}=\mathrm{B}$ & Yes \\
\hline & Gender gap between tasks & $\mathrm{M}=\mathrm{W}$ & $\mathrm{M}<\mathrm{W}$ & No \\
\hline & Math - choice & $\mathrm{G}=\mathrm{B}$ & $\mathrm{G}<\mathrm{B}$ & No \\
\hline & Word - choice & $\mathrm{G}=\mathrm{B}$ & $\mathrm{G}<\mathrm{B}$ & No \\
\hline & Gender gap between tasks & $\mathrm{M}=\mathrm{W}$ & $\mathrm{M}=\mathrm{W}$ & No \\
\hline & Risk & $\mathrm{G}<\mathrm{B}$ & $\mathrm{G}<\mathrm{B}$ & Yes \\
\hline \multirow[t]{7}{*}{$\begin{array}{l}\text { Between } \\
\text { countries }\end{array}$} & $\begin{array}{l}\text { Running - performance } \\
\text { change }\end{array}$ & Col $>$ Swe & $\mathrm{Col}=\mathrm{Swe}$ & No \\
\hline & $\begin{array}{l}\text { Skipping rope - performance } \\
\text { change }\end{array}$ & Col $>$ Swe & Col $<$ Swe & No \\
\hline & Math - performance change & Col $>$ Swe & Col=Swe & No \\
\hline & Word-performance change & Col $>$ Swe & Col=Swe & No \\
\hline & Math - choice & Col $>$ Swe & Col $<$ Swe & No \\
\hline & Word - choice & Col $>$ Swe & Col=Swe & No \\
\hline & Risk & Col $>$ Swe & Col $>$ Swe & Yes \\
\hline
\end{tabular}

G=Girls, $\mathrm{B}=$ Boys, $\mathrm{R}=$ Running, $\mathrm{S}=$ Skipping rope, $\mathrm{M}=$ Math, $\mathrm{W}=$ Word, Col=Colombia, $\mathrm{Swe}=$ Sweden. In the Results column, = indicates that the hypothesis of a difference could not be rejected. 


\section{Hypotheses and results}

In this section we test whether there is a gender gap in competitiveness and risk taking among children in Colombia and Sweden and if the type of task matters for the size of the gender gap in competitive behavior within and between the countries.

We begin by looking at gender differences in competitiveness within and between the countries in the PE part and then continue by studying competitiveness in the classroom part. We also investigate whether the gender stereotype of a certain task affects the gender gap more in Colombia compared to Sweden. We thereafter look at the gender gap in risk taking within each country and between the countries, and explore how this relates to competitive behavior. Finally, we present some additional analysis and robustness checks. All tests of the means are analyzed using the non-parametric Mann-Whitney test and a two-sided t-test. Only the p-values for the Mann-Whitney tests are displayed. ${ }^{8}$ When the two tests display conflicting results this difference is usually due to outliers. When this occurs we therefore perform the two tests on the inner quartile range (IQR, the distribution between the $25^{\text {th }}$ and the $75^{\text {th }}$ percentile), and we again only present the p-values for the Mann-Whitney test, labeled IQR. In those cases, the p-values of the full sample are presented in a footnote. All regressions are OLS unless otherwise stated.

\section{a. Basic statistics}

The study was conducted on a total of 1240 children out of which 631 were in Colombia and 609 in Sweden. ${ }^{9}$ In either country, approximately half of our sample consists of girls. We have a total of 54 primary classes in the years 3-5; 21 classes from the Bogotá region in Colombia and 33 classes from the Stockholm region in Sweden. The classes were sampled during the fall of 2009 and spring of 2010. In each class, the study started with the PE part and continued with the classroom part either the same day or the same week. Both parts of the study were overseen by at least one teacher. A majority of the 1240 children completed all tasks except the math and word tasks where each child only participated in one of the two

\footnotetext{
${ }^{8}$ We present the Mann-Whitney test since none of our variables are normally distributed when using a skewness and kurtosis test. When there is a difference between the tests in terms of significance we also report the p-values for the t-test. We have also compared whether the distributions for each reported variable differ between boys and girls using a Kolmogorov-Smirnov test. The results are similar to those reported for mean values.

${ }^{9}$ The data for Sweden was collected in parallel to the data collection in Colombia, hence the Swedish sample is not the same as in Dreber et al. (2011).
} 
tasks. ${ }^{10}$ Table 2 below provides summary statistics. For the set of variables used and variable descriptions, see Appendix Table A1.

Table 2. Summary statistics.

\begin{tabular}{lcccccc}
\hline \hline Variable & Mean & Sd & Median & N & Min & Max \\
\hline Age & 10.90 & 0.91 & 11 & 1120 & 8 & $15^{\dagger}$ \\
Class year & 4.18 & 0.73 & 4 & 1240 & 3 & 5 \\
Gender (boy=0, girl=1)* & 0.48 & 0.50 & 0 & 1222 & 0 & 1 \\
Country (Sweden=1, & 0.49 & 0.50 & 0 & 1240 & 0 & 1 \\
Colombia=0)* & & & & & & \\
\hline \hline
\end{tabular}

*(share between 0 and 1$)$

${ }^{\dagger}$ One child is 15 years old, two children are 14 years old, 20 children are 13 years old, and three children are 8 years old.

\section{b. Competition PE part}

In this section we explore competitiveness only as measured by absolute performance change in the PE part.

\section{i. Hypotheses PE part}

Previous studies indicate that the gender gap in competitiveness in running is influenced by the country in which the study is performed (Gneezy and Rustichini 2004a, Dreber et al. 2011). Colombia typically scores lower than Sweden on gender equality indices, and our prior is that such indices capture the relevant factors influencing the gender gap in competitiveness. We thus expect girls to be less competitive than boys in Colombia but not in Sweden, in both tasks. Moreover, Dreber et al. (2011) find no gender gap in Sweden in running and skipping rope, thus we expect no gender differences in Sweden in this sample.

Hypothesis 1: Girls are less competitive than boys in both running and in skipping rope in Colombia, whereas there is no gender gap in Sweden in these tasks.

In Dreber et al. (2011) the children rated skipping rope as more girlish and running as more boyish. We therefore expect the gender gap to be smaller in skipping rope than in running in Colombia, but that the task does not matter in Sweden.

Hypothesis 2: The gender gap in competitiveness is bigger in running than in skipping rope in Colombia, but not in Sweden.

\footnotetext{
${ }^{10}$ Among those that did not participate in all the PE tasks this was either due to the different experimental parts (PE and class room parts) being run at separate occasions or to time constraints (in the PE part).
} 


\section{ii. Results -- performance change PE}

Consistent with sex-stereotypic expectations, boys ran faster and girls skipped rope better on average in both stage 1 (individual performance) and in stage 2 (competition). This is the case in both Colombia and Sweden. Table 3 and Table 4 show the average performances and pvalues in both stages in Colombia and Sweden. ${ }^{11}$

Table 3. Average performance in stage 1 and in stage 2 in Colombia.

\begin{tabular}{lcccccc}
\hline \hline Colombia & \multicolumn{2}{c}{ Running } & SR & \multicolumn{2}{c}{ Skipping rope } & SR \\
\hline & Stage 1 & Stage 2 & p-value & Stage 1 & Stage 2 & p-value \\
Girls & 16.60 & 15.79 & $<0.001$ & 25.02 & 29.07 & 0.050 \\
Boys & 15.30 & 14.83 & $<0.001$ & 20.71 & 22.96 & 0.203 \\
\hline \hline
\end{tabular}

A lower time for running indicates better performance. A higher number of jumps in skipping rope indicates better performance. Signrank (SR) test p-values of performance change for girls and boys separately.

Table 4. Average performance in stage 1 and in stage 2 in Sweden.

\begin{tabular}{lcccccc}
\hline \hline Sweden & \multicolumn{2}{c}{ Running } & SR & \multicolumn{2}{c}{ Skipping rope } & SR \\
\hline & Stage 1 & Stage 2 & p-value & Stage 1 & Stage 2 & p-value \\
Girls & 15.70 & 15.15 & $<0.001$ & 58.62 & 72.97 & $<0.001$ \\
Boys & 15.33 & 14.81 & $<0.001$ & 24.45 & 33.24 & 0.003 \\
\hline \hline
\end{tabular}

A lower time for running indicates better performance. A higher number of jumps in skipping rope indicate better performance. Signrank (SR) test p-values of performance change for girls and boys separately.

With one exception, both boys and girls are competitive in terms of reacting to competition: they increase their performance when competing compared to performing the task individually in both Colombia and Sweden. When skipping rope, boys in Colombia are the only ones who do not increase their performance significantly when competing.

Testing whether there is a significant gender gap in competitiveness as measured by performance change in running, we find no gender gap in Colombia (IQR: $\mathrm{p}=0.236$ ) or Sweden $(\mathrm{p}=0.875) .{ }^{12}$ See Figure 1 . The running result in Sweden is in line with what Dreber et al. (2011) found. In skipping rope, there is no gender gap in performance change in Colombia ( $p=0.379$ ). In Sweden, there is some evidence that girls compete more than boys (IQR: $\mathrm{p}=0.014) .{ }^{13}$ See Figure 2. This latter result differs from the result on skipping rope

\footnotetext{
${ }^{11}$ Note that the children were not aware of the second stage when performing the first stage.

${ }^{12}$ Using the full sample in Colombia, the non-parametric test gives a significant gender difference $(p=0.009)$ whereas the parametric test gives a borderline insignificant result $(\mathrm{p}=0.095)$.

${ }^{13}$ Using the full sample in Sweden, the Mann-Whitney test gives a significant $p$-value $(p=0.021)$ whereas the $p$ value from the $\mathrm{t}$-test is insignificant $(\mathrm{p}=0.348)$.
} 
found in Sweden in Dreber et al. (2011). This is probably due to the larger sample size in this study. However, the gender gap in skipping rope disappears when using a relative measure of performance change, making this finding inconclusive.

Figure 1. Average performance change in running (stage 2 - stage 1), by gender.

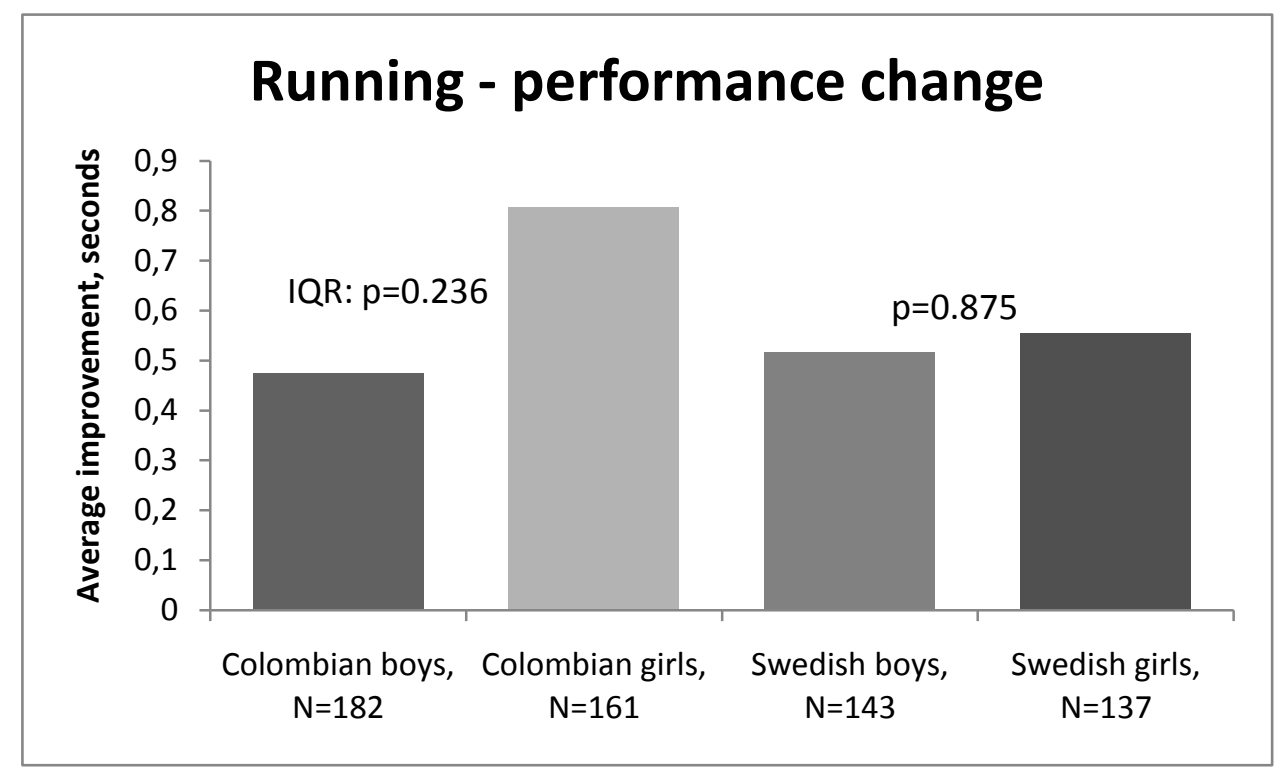

Figure 2. Average performance change in skipping rope (stage 2 -stage 1), by gender.

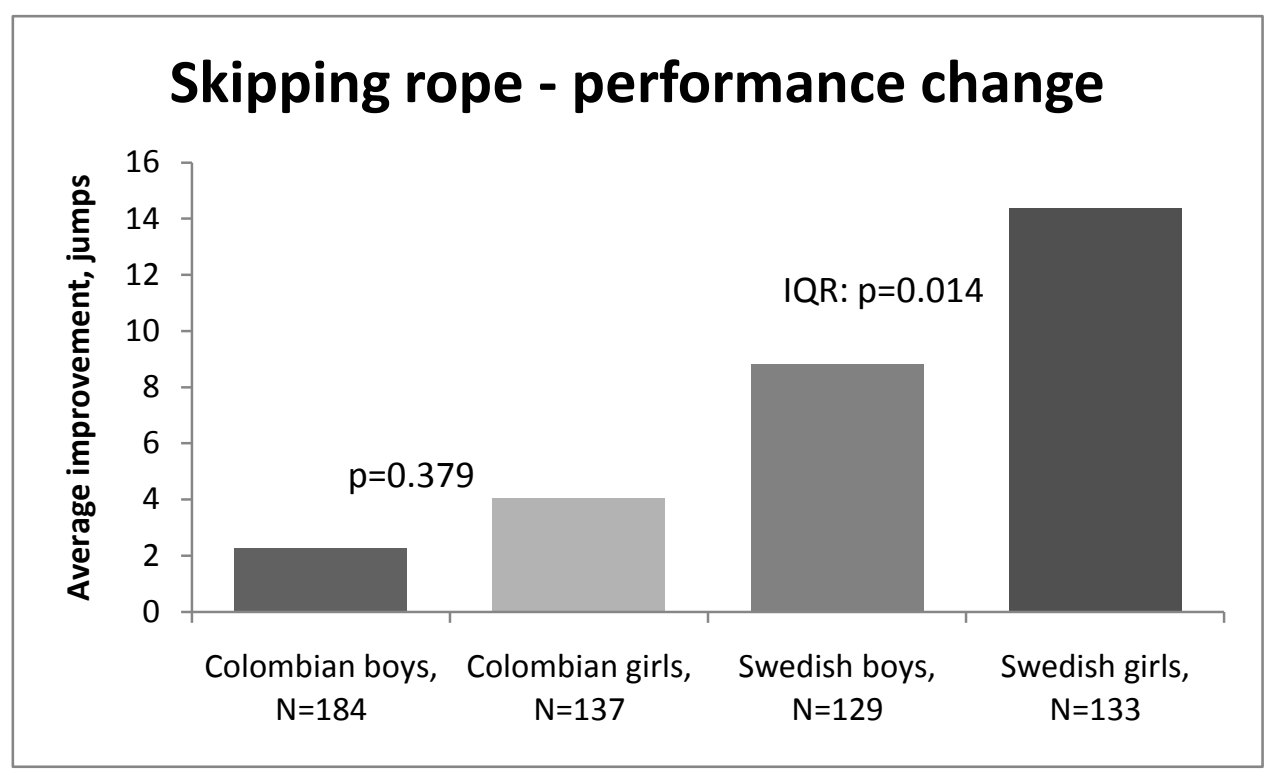

We also test whether the gender gaps differ between Colombia and Sweden in a regression analysis. Using the parametric tests we found no gender gap within each country, thus there are no significant differences in the regression analysis. However, when we add control 
variables, there is some evidence of a larger gender gap in skipping rope in Sweden than in Colombia. ${ }^{14}$ See Online Appendix Tables OA1-OA2.

Testing Hypothesis 2, we look at whether the gender gap in competitiveness is bigger in running than in skipping rope in either country with a regression analysis. In order to be able to compare performance change between running and skipping rope we look at relative performance change rather than absolute performance change. See the first section of the Appendix for an additional analysis of relative performance change. We find no evidence of the gender gap being influenced by the task in neither Colombia nor Sweden. See Online Appendix Tables OA3-OA4.

We thus find no support for Hypothesis 1 or for Hypothesis 2. Boys and girls are equally competitive in running in both Colombia and Sweden; there is no gender gap in competitiveness in skipping rope in Colombia whereas there is some evidence of girls being more competitive than boys in skipping rope in Sweden. However the gender gaps in relative performance change display no significant differences between the two tasks.

The gender of the opponent is known in both running and skipping rope. There is some previous work suggesting that the gender of the opponent matters, but the results are mixed (see, e.g., Croson and Gneezy 2009). In our sample the only opponent effects we find are that girls in Colombia and boys in Sweden run significantly faster when competing against girls ( $\mathrm{p}=0.001$ and $\mathrm{p}=0.020$ respectively).

Table 5. Gender of opponent effects, p-values.

\begin{tabular}{|c|c|c|c|c|c|c|c|c|}
\hline & \multicolumn{4}{|c|}{ Colombia } & \multicolumn{4}{|c|}{ Sweden } \\
\hline & \multicolumn{2}{|c|}{ Running } & \multicolumn{2}{|c|}{ Skipping } & \multicolumn{2}{|c|}{ Running } & \multicolumn{2}{|c|}{ Skipping } \\
\hline & $\mathrm{N}$ & p-value & $\mathrm{N}$ & p-value & $\mathrm{N}$ & $\mathrm{p}$-value & $\mathrm{N}$ & p-value \\
\hline $\begin{array}{l}\text { Girls: boys } \\
\text { vs girls }\end{array}$ & $54 / 107$ & 0.001 & $65 / 72$ & 0.264 & $70 / 58$ & 0.700 & $50 / 75$ & $0.407^{\dagger}$ \\
\hline $\begin{array}{l}\text { Boys: boys } \\
\text { vs girls }\end{array}$ & $126 / 56$ & $0.039^{\ddagger}$ & $120 / 64$ & 0.782 & $68 / 68$ & 0.020 & $73 / 51$ & 0.499 \\
\hline \multicolumn{9}{|c|}{$\begin{array}{l}\text { IQIQR } \\
{ }^{f} \text { This is not significant using a t-test }(\mathrm{p}=0.144) \text { or with } \mathrm{IQR}(\mathrm{p}=0.646) \text {. }\end{array}$} \\
\hline \multicolumn{9}{|c|}{$\begin{array}{l}{ }^{14} \text { When performing the regression analysis we compare the results from a regression with no control variables } \\
\text { with regressions using two sets of controls. The first set of controls contain actual individual performance, } \\
\text { expected individual performance (i.e. beliefs), age and risk preferences. These controls are included since } \\
\text { previous work has shown that these are factors that play a role for both competitiveness measures. The second } \\
\text { set of controls includes all variables from the first set plus four additional variables from the questionnaire that } \\
\text { control for how gendered the children perceive the tasks to be and how important they consider competing to be. } \\
\text { These four variables were included to control for motivational factors that may play a role in competitiveness. }\end{array}$} \\
\hline
\end{tabular}




\section{c. Competition classroom}

In this part we study competitiveness in math and word search as measured by performance change and the choice whether to compete or not.

\section{i. Hypotheses}

There are no previous studies exploring the gender gap in different classroom tasks, such as math and word tasks, among children. Given the literature on performance change in the PE tasks among children we expect boys to be more competitive than girls in Colombia but not in Sweden. Since previous studies have found that competitiveness sometimes depends on the task for adults, we expect the gender gap to be bigger in math than in word search.

Hypothesis 3: Girls are less competitive than boys in Colombia in terms of performance change in both math and word search, whereas there is no gender gap in Sweden.

Hypothesis 4: The gender gap in competitiveness in terms of performance change will be bigger in the math task than in the word task in Colombia, but not in Sweden.

In the current sample, the children rated math as more boyish and word search as more girlish (see section 4f). Moreover, previous literature on adults show that men are more competitive when it comes to choosing to compete in math in western societies typically ranked less equal compared to Sweden, thus we expect girls to choose competition less than boys in Colombia but not in Sweden, for both tasks. ${ }^{15}$ We also expect the gender gap to be bigger in math than in word search in Colombia but not in Sweden.

Hypothesis 5: Girls are less competitive than boys in Colombia in terms of choice in math and word tasks, whereas there is no gender gap in Sweden.

Hypothesis 6: The gender gap in competitiveness in terms of choice will be bigger in the math task than in the word task in Colombia but not in Sweden.

\section{ii. Results - performance change}

When exploring performance in stage 1 (individual performance: piece-rate scheme), we find support for the math and word tasks being gendered in Sweden but not in Colombia. Performance in stage 1 differs between boys and girls in Sweden; boys perform better in the

\footnotetext{
${ }^{15}$ E.g. Niederle and Vesterlund (2007) conduct their experiment on adults in the US. US is ranked $19^{\text {th }}$ in the Global Gender Gap Report 2010 (Hausmann et al. 2010).
} 
math task and girls perform better in the word task (Math: $p=0.017$, Word: $p=0.043$ ). In Colombia we find no gender differences in stage 1 (Math: $\mathrm{p}=0.746$, Word: $\mathrm{p}=0.172$ ). Tables 6 and 7 below display the average piece-rate performances and the average forced tournament performances.

Table 6. Average performance in stage 1 and in stage 2 in Colombia.

\begin{tabular}{lcccccc}
\hline \hline Colombia & \multicolumn{2}{c}{ Math } & SR & \multicolumn{2}{c}{ Word } & SR \\
\hline & Stage 1 & Stage 2 & p-value & Stage 1 & Stage 2 & p-value \\
Girls & 6.57 & 7.11 & 0.163 & 3.37 & 4.22 & $<0.001$ \\
Boys & 7.06 & 7.23 & 0.448 & 3.21 & 4.25 & $<0.001$ \\
\hline \hline
\end{tabular}

SR=Signrank test.

Table 7. Average performance in stage 1 and in stage 2 in Sweden.

\begin{tabular}{lcccccc}
\hline Sweden & \multicolumn{2}{c}{ Math } & SR & \multicolumn{2}{c}{ Word } & SR \\
\hline & Stage 1 & Stage 2 & p-value & Stage 1 & Stage 2 & p-value \\
Girls & 9.60 & 10.73 & $<0.001$ & 9.41 & 9.81 & 0.303 \\
Boys & 11.22 & 11.11 & 0.378 & 8.28 & 8.34 & 0.705 \\
\hline \hline
\end{tabular}

SR=Signrank test.

In Colombia, both boys and girls are competitive in word search in terms of reacting to competition, whereas this in not the case in math. In Sweden, only girls increase their performance significantly when forced to compete in the math task, but as for the result on skipping rope the gender difference disappears when we use a relative performance measure.

When we test whether there is a gender difference in competitiveness in Colombia and Sweden in either task, we find a gender gap only in Sweden and only in math: Girls in Sweden increase their performance in math significantly more than boys do $(p=0.002)$. In Colombia however, there is no gender difference in performance change in the math task $(p=0.747)$ or in the word task $(p=0.172)$. In Sweden, there is no gender gap in competitiveness in the word task $(\mathrm{p}=0.555)$. See Figures 3 and 4. 
Figure 3. Average change in math exercises (stage 2 - stage 1), by gender.

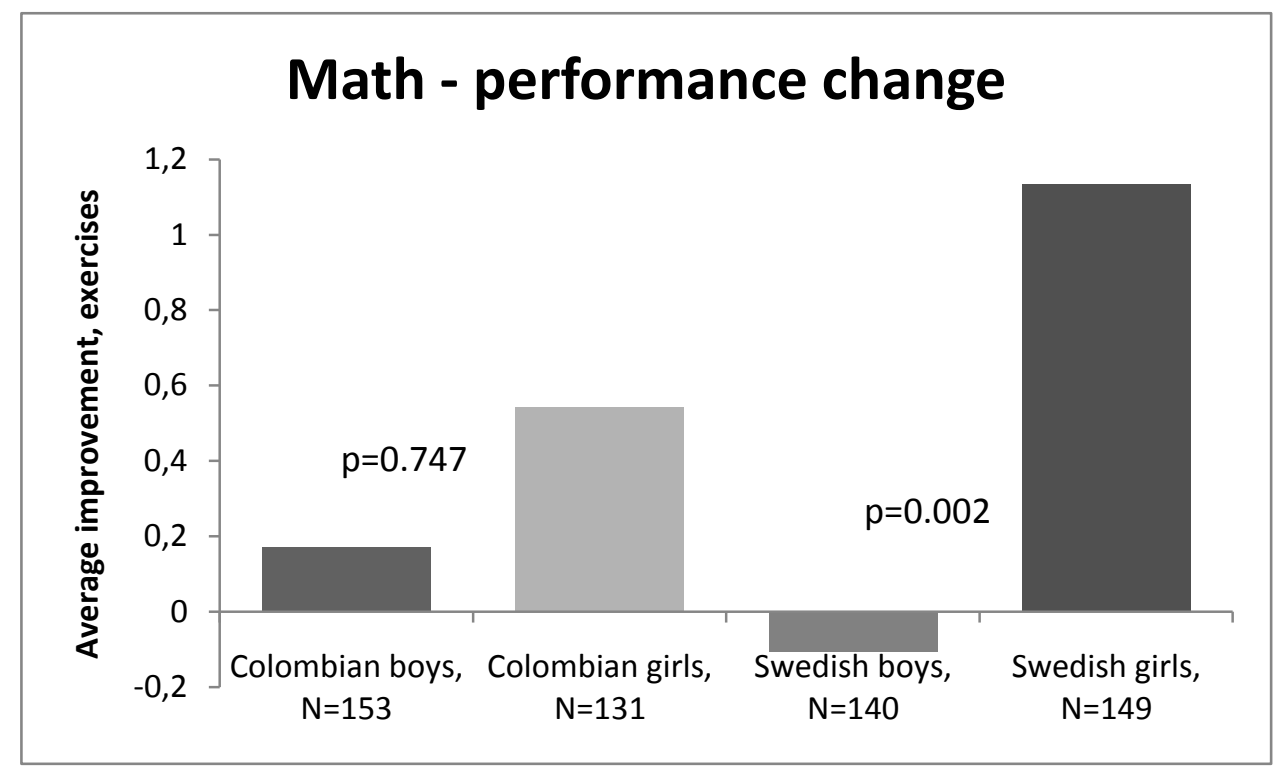

Figure 4. Average change in words found (stage 2 - stage 1), by gender.

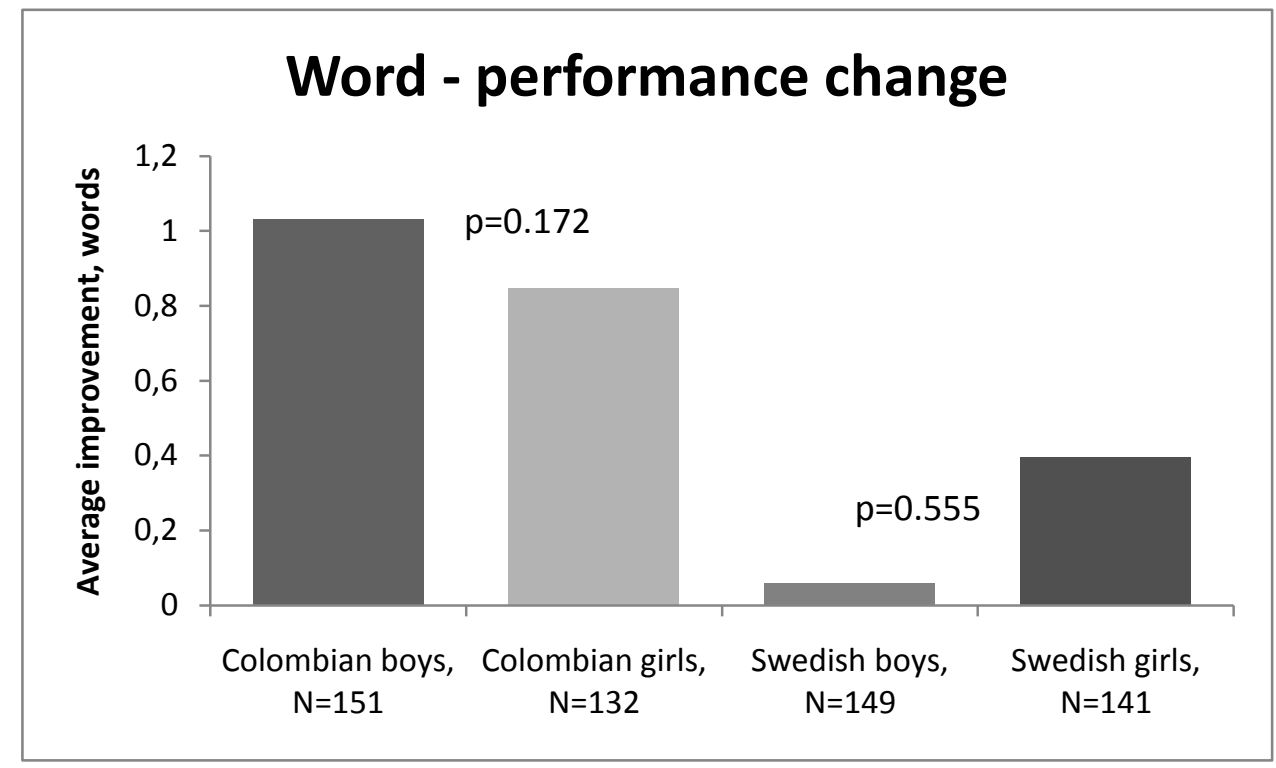

In a regression analysis we find that the gender gap in performance change in math is not significantly bigger in Sweden than in Colombia $(\mathrm{p}=0.214)$. When adding controls, the results remain similar. See Online Appendix Tables OA5-OA6. There is also no significant difference in the gender gap in the word task between Colombia and Sweden $(p=0.354)$.

We further test whether the gender gap in competitiveness in terms of relative performance change is bigger in math than in word search in either country. We find no evidence of this. See Online Appendix Tables OA7-OA8. 
Little support is thus found for Hypotheses 3 and 4. There is no gender gap in competitiveness as measured by performance change in Colombia in either task or in the word task in Sweden, whereas girls in Sweden are more competitive than boys in the math task. Yet, in a regression analysis of relative performance change, the gender gap does not seem to be influenced by the task.

\section{iii. Results - choice}

In stage 3, when the children could choose whether or not to compete, we find that boys and girls in Colombia are equally likely to choose to compete in math and word search (Math: $\mathrm{p}=0.704$, Word: $\mathrm{p}=0.689) .{ }^{16}$ In Sweden, on the other hand, boys are significantly more likely to choose to compete both in math and in word search compared to girls: $44 \%$ of the boys and only $19 \%$ of the girls chose to compete in math $(\mathrm{p}<0.001)$, whereas in word search the corresponding numbers are 39\% and 27\% (p=0.045). See Figures 5 and 6.

Figure 5. Share choosing to compete in math, by gender.

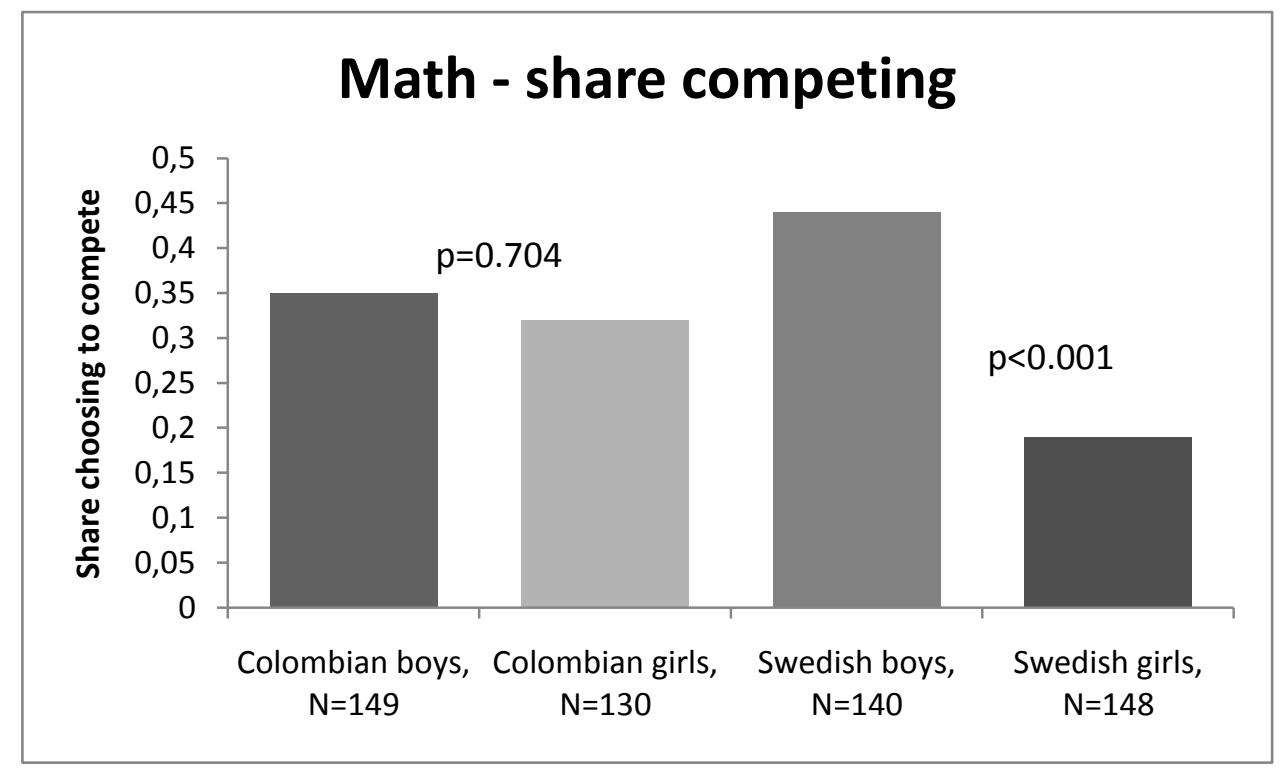

\footnotetext{
${ }^{16}$ Among Colombian children, $35 \%$ of the boys and $32 \%$ of the girls chose to compete in math, with the corresponding numbers for word search being $26 \%$ and $29 \%$ respectively. In this subsection we use the nonparametric Chi-square test and the parametric test of equal proportions.
} 
Figure 6. Share choosing to compete in word search, by gender.

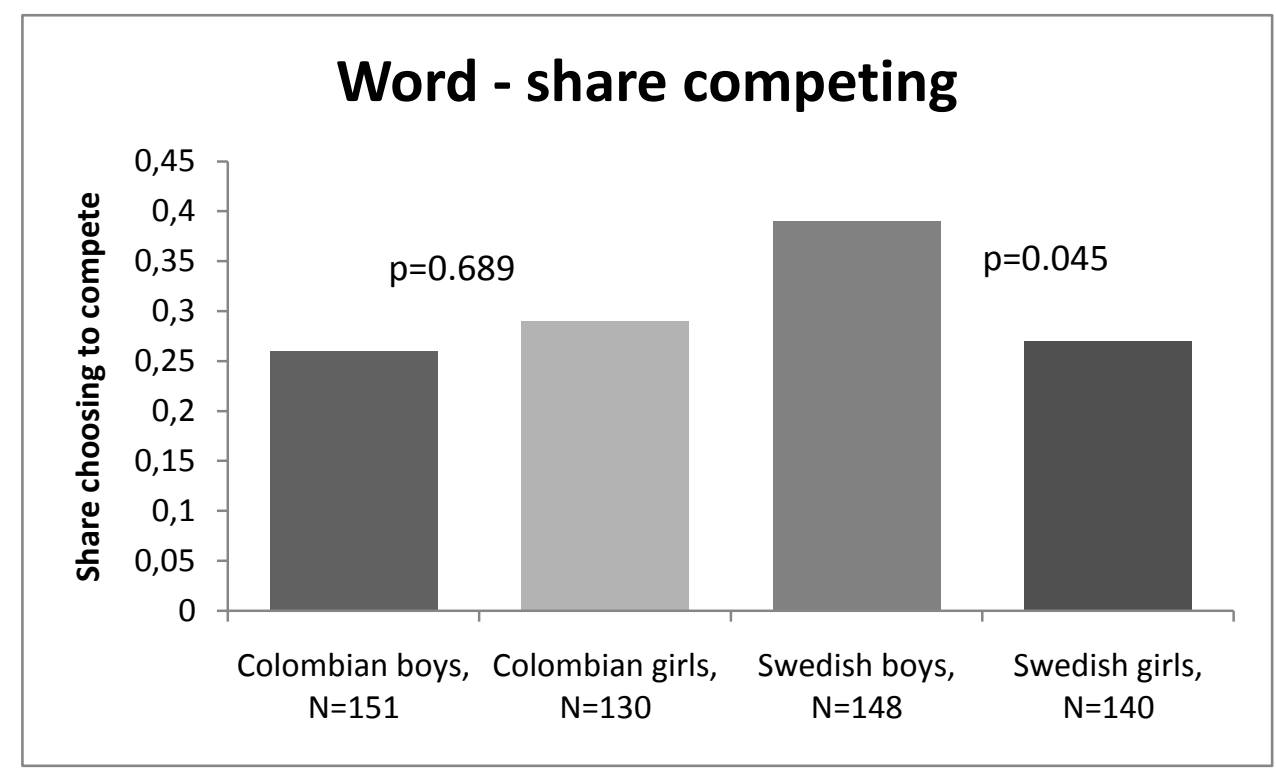

Comparing the gender gap in choice between Colombia and Sweden, we find a significant difference in the math task. The gender gap in math is significantly larger in Sweden than the gender gap in Colombia ( $\mathrm{p}=0.003)$. In word search we find a borderline insignificant gender gap between the two countries $(\mathrm{p}=0.068)$. However, when adding controls to the regression analysis (see footnote 15), the gender gap in competitiveness as measured by choice is significantly larger only in the word task in Sweden. See Online Appendix Tables OA9-A10.

Testing whether the gender gap in choice is bigger in math than in word search, we find some evidence of this being the case in Colombia (No controls: $p=0.496$, Control Set 1: $p=0.056$, Control Set 2: $\mathrm{p}=0.042$ ) but not in Sweden. ${ }^{17}$ See Online Appendix Tables OA11-OA12.

We thus find no support of hypothesis 5 . When it comes to competitiveness as measured by choice we find a gender gap in competitiveness in both tasks in Sweden but not in Colombia. It is however only the gender gap in math that is significantly different between the countries. Moreover, in Colombia, but not in Sweden, there is some support of hypothesis 6, with the gender gap in choice in math being somewhat bigger than in word search.

To summarize the section on competitiveness: when measuring competitiveness as a performance reaction to a competitive setting we find that girls are more competitive than boys in Sweden when it comes to math, and some evidence that this is also the case in skipping rope. When looking at the choice of competition we again find a gender gap only in

\footnotetext{
${ }^{17}$ The gender gap in choice reaches significance when adding controls in Colombia in this regression analysis, it disappears however when using the other risk measure.
} 
Sweden, where boys choose to compete more often than girls in both math and word search (controlling for performance). Finally, there is only little evidence of the task being important for the gender gap in competitiveness, and according to a regression analysis this is mainly the case for competition choice in Colombia.

\section{d. Risk preferences}

In this section we explore the gender gap in risk preferences measured from incentivized lotteries conducted in the class room.

\section{i. Hypotheses}

Previous work finds mixed results on the existence of a gender gap in risk taking among children and adolescents (Harbaugh et al. 2004, Booth and Nolen 2009b, Borghans et al. 2009). Among the studies that do find a gender gap, boys are found to be more risk taking than girls. We thus expect boys to take more risk in both countries, but given that Colombia scores lower on gender equality indices we expect the gap to be bigger in Colombia.

Hypothesis 7: Boys are more risk taking in both countries.

Hypothesis 8: The gender gap is greater in Colombia than in Sweden.

\section{ii. Results - risk}

In the joint sample (including children in both Colombia and Sweden), 25\% of the children were inconsistent in their choices of the safe option versus the lottery (coin flip). In general, the children are significantly more inconsistent in Colombia (29\%) compared to Sweden $(21 \%)(\mathrm{p}=0.001){ }^{18}$ There is however no gender difference in being inconsistent in either country (Colombia: $\mathrm{p}=0.927$, Sweden: $\mathrm{p}=0.220$ ). We also measure risk preferences in terms of the number of risky choices chosen, in order to not exclude inconsistent choices. Using this outcome measure the results are similar to those presented here.

\footnotetext{
${ }^{18}$ These shares are higher than what is typically found among adults, and could be an indication of a limited understanding of probabilities in this age group. Future research should take this into account.
} 
Table 8. Summary table risk measures.

\begin{tabular}{lcccccc}
\hline \hline Variable & Mean & Sd & Median & N & Min & Max \\
\hline Risk (certainty equivalent) & 4.00 & 2.23 & 3.5 & 872 & 1 & 8.75 \\
Inconsistent answers & 0.25 & 0.43 & 0 & 1166 & 0 & 1 \\
Number of risky choices & 2.54 & 1.66 & 3 & 1138 & 0 & 6 \\
\hline \hline
\end{tabular}

We find a gender gap in risk taking in both countries, with boys taking more risk. In Colombia, boys take $40 \%$ more risk than girls $(\mathrm{p}<0.001)$, with the corresponding number in Sweden being $15 \%(\mathrm{p}<0.001)$. See Figure 7.

Figure 7. Risk taking, by gender.

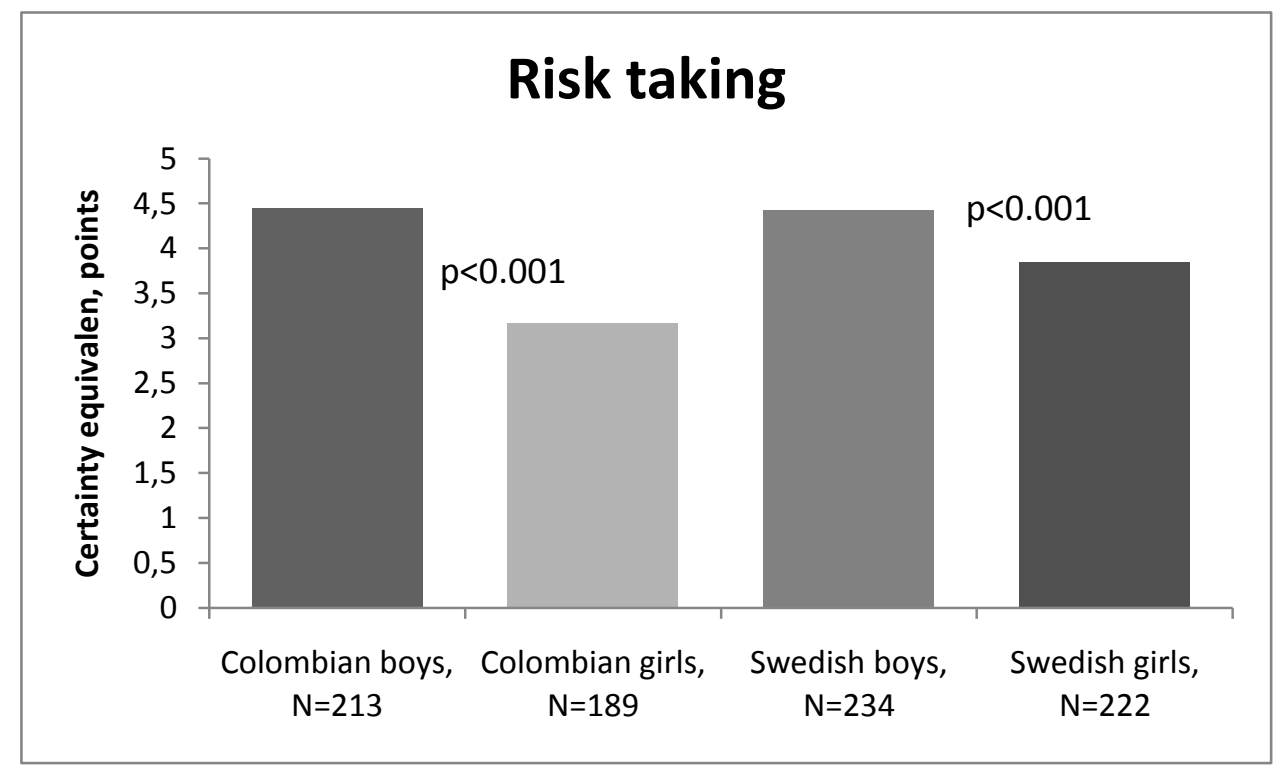

Comparing Colombia and Sweden, we find that Colombian children take less risk than Swedish children $(\mathrm{p}<0.001)$. This result is driven by the difference between Colombian and Swedish girls, since boys are equally risk taking in the two countries. When testing the size of the gender gaps, we find a significantly larger gender gap in Colombia compared to Sweden $(\mathrm{p}=0.018)$.

Thus, hypotheses 5 and 6 are supported: boys take more risk in both countries, and the gender gap is greater in Colombia than in Sweden.

\section{e. Competitiveness and risk preferences}

We also explore the relationship between risk taking and competitiveness, since the two things often are related yet are two separate concepts, and there typically are gender 
differences in both preferences. We find a positive relationship between risk taking and choosing to compete in Sweden $(\mathrm{p}<0.001)$. In Colombia there seems to be no such relationship $(\mathrm{p}=0.121)$. Studying the sample split by gender within each country, both girls and boys display the same positive correlation pattern in Sweden (Girls: $p=0.011$, Boys: $\mathrm{p}<0.001)$. In Colombia boys but not girls display a positive pattern between choice of competition and risk taking behavior (Girls: $\mathrm{p}=0.926$, Boys: $\mathrm{p}=0.077) .{ }^{19}$

Niederle and Vesterlund (2007) find that the gender gap in risk preferences only explains part of the gender gap in competitiveness as measured by choice among adults, and our results support this. Our results indicate that the cross-country factors in play seem to affect risk taking and competitiveness differently.

\section{f. Additional analysis and robustness checks}

In this section we provide some additional analysis of our findings. More tests and an analysis of differences in variance and relative performance can also be found in the first section of the Appendix.

\section{Performance beliefs}

We asked the children to rank their believed performance in math and word search relative to their classmates in stage 2. We then measure confidence as the discrepancy between selfassessed and actual performance. We find no gender gap in this confidence measure when it comes to math or word search in either country. On average, the Colombian children seem to be more overconfident than Swedish children $(\mathrm{p}<0.001)$.

It is surprising that we don't find that overconfidence, or a gender difference in beliefs about performance, explains part of the gender gap given that it has previously been shown to play an important role (e.g. Niederle and Vesterlund 2007). It is also surprising that there is no gender gap in overconfidence in either task in either country, since these results differ from those of Dahlbom et al. (2011), who find that among 14-year old children in Sweden, boys are overconfident and girls are underconfident in terms of math performance. Our results also differ from those of Jakobsson et al. (2010), who find that boys in El Salvador are overconfident and girls are underconfident in math whereas there is no gender gap in a more

\footnotetext{
${ }^{19}$ The p-values come from testing equality of distribution of risk between those who chose competition to those who did not, using a Kolmogorov Smirnov test. This is the case for both indicators of risk preferences: the certainty equivalent to the lottery, or the number of risky choices they select out of all choices.
} 
gender neutral task such as performance in social science, where both boys and girls are overconfident. The children in our study are younger than those in Dahlbom et al. (2011) and Jakobsson et al. (2010), and we ask a retrospective question whereas these other two studies ask the children about their expected performance on a math test that will be performed later. This may explain the discrepancy between our results.

\section{Do the children perceive competing as important, and tasks as gendered?}

The final element in the classroom part is a survey where we elicit perceptions of how boyish/girlish the children considered running, skipping rope, math and word search to be. We further asked how boyish/girlish they considered competing in these tasks to be. We used a scale from 0 to 10 where a lower number indicates rating the task as more girlish and a higher number as more boyish ( $0=$ very girlish, $5=$ neutral, $10=$ very boyish). We used a similar scale to elicit how important the children consider competing against a boy and against a girl to be $(0=$ not at all important, $10=$ very important $)$.

In both countries, boys rate competition as more important compared to girls (Colombia: $\mathrm{p}=0.009$, Sweden: $\mathrm{p}<0.001$ ). In Colombia, both girls and boys believe that it is more important to compete against a boy than against a girl (Girls: $p=0.003$, Boys: $p<0.001$ ). Girls in Sweden rate competing against a boy as being more important compared to competing against a girl $(\mathrm{p}<0.001)$, whereas boys rate it as equally important $(\mathrm{p}=0.347)$. This does not correspond to what we observe in terms of the gender of opponent effect in performance change. Swedish boys actually change their performance more when competing against a girl in running, see Table 5. Children in both Colombia and Sweden perceive math and running as being significantly more boyish ( $\mathrm{p}<0.001$ for both countries and both tasks) whereas skipping rope and word search are seen as being more girlish $(\mathrm{p}<0.001$ for both countries and both tasks). ${ }^{20}$ Boys and girls tend to agree in these ratings, except that boys in both Colombia and Sweden perceive word search to be more girlish whereas girls perceive it to be more gender neutral (Colombia: Girls: $\mathrm{p}=0.111$, Boys: $\mathrm{p}<0.001$, Sweden: Girls: $\mathrm{p}=0.288$, Boys: $\mathrm{p}<0.001$ ). To explore exact point estimates and p-values see Appendix table A2.

\footnotetext{
${ }^{20}$ When testing for how boyish and girlish the children perceive the tasks to be we use a sign-rank (Wilcoxon) test to explore the deviation from the neutral rating.
} 


\section{Discussion}

In studies on adults, men are typically more competitive, measured by both performance change in response to competition and the choice to compete, as well as more risk taking than women. This difference in behavior may explain part of the gender gap observed in many areas in society, including why men are more likely to be in top positions in most sectors. The foundations of the gender gap are currently being investigated in a number of ways. For example, some studies find that the type of task used to measure competitiveness matter and influences the extent to which there is a gender gap in competitiveness (Gneezy and Rustichini 2004b, Grosse and Riener 2010, Günther et al. 2010), whereas other studies find no effect (Wozniak et al. 2010, Dreber et al. 2011). The gender gap in competitiveness among adults, as measured by choice, has been shown to disappear with performance feedback (Wozniak et al. 2010) and in setups where uncertainty about performance is minimized (Niederle and Yestrumskas 2008). The gender difference in performance change also vanishes with repetition of the competition (Cotton et al. 2009).

It has also been shown that the social and cultural environment in which the study is conducted plays an important role in explaining the gender gap in competitiveness (e.g. Gneezy and Rustichini 2004a, Gneezy et al. 2009, Dreber et al. 2011). For example, Andersen et al. (2010) find that boys become more competitive than girls around the age of 13-15 in a patriarchal society but not in a matrilineal society, where there is no gender gap in any age group. These discrepancies suggest that there is a need for more studies in a wide range of countries.

There are also studies that attempt to address the hormonal impact on the gender gap in preferences for competition and risk among adults (see Dreber and Hoffman 2010 for a review of this literature). These studies find conflicting results on the impact of the menstrual cycle on competitiveness (Buser 2009, Wozniak et al. 2010) and on risk taking (Chen et al. 2005, Buser 2009, Pearson and Schipper 2009). The same is true for testosterone and risk taking (Apicella et al. 2008, Sapienza et al. 2009, Zethraeus et al. 2009), whereas the only study that we are aware of that looks at testosterone and competitiveness finds no relationship (Apicella et al. 2011). More work is thus needed in this field with inconclusive results, as well as studies looking at hormonal correlates among children and adolescents.

In this paper we study the gender gap in competitiveness and risk taking among children aged 9-12 in Colombia and Sweden. We consistently find no gender gap in competitiveness in 
Colombia, a country considered less gender equal than Sweden. We find clear evidence that boys choose competition more than girls in both math and word search in Sweden, where there is also some indication of girls being more competitive than boys in skipping rope and math when it comes to performance change. Our hypotheses on competitiveness are thus not supported. Meanwhile, boys are more risk taking in both Colombia and Sweden, and the gender gap is greater in Colombia than in Sweden. This supports our hypotheses on risk preferences.

It is puzzling why our priors are not supported for competitiveness while they are supported for risk taking. Colombia and Sweden differ in many aspects, including the level of gender equality. Our results indicate that competitiveness and risk preferences may be affected in different ways (if at all) by social norms related to gender equality. We hypothesized that the gender equality of the country would be a good proxy of the gender gap. Our sample of two countries is obviously very small, but thus far the gender equality of the country seems to not be a good proxy of the gender gap in competitiveness. This should be elaborated further in more extensive studies. Moreover, focusing on identifying the specific components and how they relate to gender differences in competition, be it the country's educational gender gap, labor market gender gap, or political gender gap, is also a potentially fruitful avenue for future research.

Exploring the gender gap in preferences for competition and risk as we have done here contributes to further our understanding of the cultural impact on the gender gap in preferences, and also gives us more insights about the gender gap in preferences among children, which is not necessarily the same as among adults. It would be interesting to explore other age groups, including adults in a cross-cultural study, as well as to explore other types of preferences. This is an endeavor that will require collaborations among researchers across a wide range of countries, perhaps including other types of social and cognitive scientists for complementary perspectives of the gender gap and the development of preferences. 


\section{Role of the funding source}

The funding sources had no involvement in any part of the study.

\section{References}

Andersen, S., Ertac, S., Gneezy, U., List, J., Maximiano, S., 2010. Age and gender differences in competitiveness: evidence from matrilineal and patriarchal societies. Mimeo.

Apicella, C.L., Dreber, A., Campbell, B., Gray, P.B., Hoffman, M., Little, A.C., 2008. Testosterone and financial risk preferences. Evolution and Human Behavior 29, 384-390.

Apicella, C.L., Dreber, A., Gray, P.B., Hoffman, M., Little, A.C., Campbell, B.C., 2011. Androgens and competitiveness in men. Journal of Neuroscience, Psychology and Economics 4, 54-62.

Booth, A.L., Nolen, P.J., 2009a. Choosing to compete: How different are girls and boys? IZA Discussion Paper 4027.

Booth, A.L., Nolen, P.J., 2009b. Gender differences in risk behaviour: Does nurture matter? IZA Discussion Paper 4026.

Borghans, L., Golsteyn, B., Heckman, J.J., Meijers, H., 2009. Gender differences in risk aversion and ambiguity aversion. Journal of the European Economic Association 7, 649-658.

Buser, T. 2009. The impact of female sex hormones on competitiveness. Mimeo.

Cárdenas, J.-C., Dreber, A., von Essen, E., Ranehill, E., 2011. Gender and cooperation in children: Experiments in Colombia and Sweden. Scandinavian Working Papers in Economics. No. 735. SSE/EFI Working Paper Series in Economics and Finance. Stockholm School of Economics.

Chen, Y., Katuscak, P., Ozdenoren, E., 2005. Why can't a woman bid more like a man? Mimeo.

Cotton, C., McIntyre, F., Price, J., 2009. Gender differences disappear with exposure to competition. Mimeo.

Croson, R., Gneezy, U., 2009. Gender differences in preferences. Journal of Economic Literature 47, 1-27.

Dahlbom L., Jakobsson, A., Jakobsson, N., Kotsadam, A., 2011. Gender and overconfidence: Are girls really overconfident? Applied Economics Letters 18, 325-327.

Dreber, A., von Essen, E., Ranehill, E., 2011. Outrunning the gender gap: Boys and girls compete equally. Experimental Economics. doi: 10.1007/s10683-011-9282-8 
Dreber, A., Hoffman, M., 2010. Biological basis of sex differences in risk aversion and competitiveness. Mimeo.

Gneezy, U., Rustichini, A., 2004a. Gender and competition at a young age. American Economic Review 94, 377-381.

Gneezy, U., Rustichini, A., 2004b. Executives verses teachers: Gender, competition and self selection. Mimeo.

Gneezy, U., Leonard, K., List, J., 2009. Gender differences in competition: Evidence from a matrilineal and a patriarchal society. Econometrica 77, 1637-1664.

Grosse, N.D., Reiner, G., 2010. Explaining gender differences in competitiveness: Gendertask stereotypes. Jena Economic Research Paper 2010 - 017.

Günther, C., Ekinci, N.A., Schwieren, C., Strobel, M., 2010. Women can't jump? - An experiment on competitive attitudes and stereotype threat. Journal of Economic Behavior and Organization 75, 395-401

Harbaugh, W.T., Krause, K., Vesterlund, L., 2002. Risk attitudes of children and adults: Choices over small and large probability gains and losses. Experimental Economics 5, 53-84.

Hausmann, R., Tyson, L., Zahidi, S., 2010. The Global Gender Gap Report. Geneve: World Economic Forum.

Jakobsson, N., Kotsadam, A., Levin, M., 2010. Gender and overconfidence: Effects of context, gender stereotypes and peer groups. Mimeo.

Niederle, M., Vesterlund, L., 2007. Do women shy away from competition? Do men compete too much? Quarterly Journal of Economics 122, 1067-1101.

Niederle, M., Yestrumskas, A.H., 2008. Gender differences in seeking challenges: The role of institutions. Mimeo.

Pearson, M., Schipper, B.C., 2009. Menstrual cycle and competitive bidding. Mimeo.

Sapienza, P., Zingales, L., Maestripieri, D., 2009. Gender differences in financial risk aversion and career choices are affected by testosterone. Proceedings of the National Academy of Sciences 106, 15268-15273.

Sutter, M., Rützler, D., 2010. Gender differences in competition emerge early in life. IZA Discussion Paper 5015.

Wozniak, D., Harbaugh, W.T., Mayr, U., 2010. Choices about competition: Differences by gender and hormonal fluctuations, and the role of relative performance feedback. Mimeo.

Zethraeus, N., Kocoska-Maras, L., Ellingsen, T., von Schoultz, B., Hirschberg, A.L., Johannesson, M., 2009. A randomized trial of the effect of estrogen and testosterone on economic behavior. Proceedings of the National Academy of Sciences 106, 6535-6538. 


\section{Appendix}

\section{Relative performance change}

We also conduct the same analysis for performance with relative performance change instead of absolute performance change, where relative performance change is defined as ((performance in stage 2 - performance in stage 1)/performance in stage 1$)$. With this analysis the gender differences that we found using absolute performance change in skipping rope and math in Sweden disappear. Hence, we find no gender gap in competitiveness in neither Colombia nor Sweden in any task when it comes to relative performance change.

Table A1. Set of variables used, variable description.

\begin{tabular}{ll}
\hline \hline \multicolumn{1}{c}{ Variable } & \multicolumn{1}{c}{ Variable description } \\
\hline Sweden & Dummy variable for country, Sweden=1 \\
Female & Dummy variable for gender, girl=1 \\
Female*Sweden & Interaction variable between gender and country \\
Individual performance & Performance in the non-competitive setting \\
Competitive performance & Performance in the competitive setting \\
Running & Dummy variable type of PE task, running=1 \\
Math & Dummy variable type of lab task, math=1 \\
Age & Age in years \\
Risk & Certainty equivalent in risk task \\
Expected performance & Participants' guessed rank in stage 2 \\
Importance winning female opponent & Importance of winning against a girl, scale 1-10 \\
Importance winning male opponent & Importance of winning against a boy, , scale 1-10 \\
Running gendered & How gendered running is, scale 1-10 \\
Skipping gendered & How gendered skipping is, scale 1-10 \\
Math gendered & How gendered math is, scale 1-10 \\
Word gendered & How gendered word search is, scale 1-10 \\
\hline \hline
\end{tabular}




\section{Online Appendix}

Table OA1. Performance change running.

\begin{tabular}{lccc}
\hline \hline VARIABLES & No controls & Set 1 & Set 2 \\
& $(1)$ & $(2)$ & $(3)$ \\
\hline Sweden & -0.0426 & 0.0798 & 0.0957 \\
& $(0.161)$ & $(0.178)$ & $(0.188)$ \\
Female & $-0.331^{* *}$ & 0.178 & 0.194 \\
& $(0.156)$ & $(0.188)$ & $(0.205)$ \\
Female*Sweden & 0.293 & -0.155 & -0.213 \\
& $(0.233)$ & $(0.256)$ & $(0.270)$ \\
Individual & & $-0.314^{* * *}$ & $-0.315^{* * *}$ \\
performance & & $(0.0342)$ & $(0.0345)$ \\
& & -0.0721 & -0.0594 \\
Age & & $(0.0703)$ & $(0.0710)$ \\
& & -0.000132 & -0.00294 \\
Risk & & $(0.0277)$ & $(0.0281)$ \\
Importance winning & & & -0.0246 \\
female opponent & & & $(0.0194)$ \\
Importance winning & & & 0.00423 \\
male opponent & & & \\
Running gendered & & & $(0.0196)$ \\
& & & -0.00657 \\
Observations & & & $(0.0271)$ \\
R-squared & & & 416 \\
\hline Standard & & & 0.181 \\
\hline
\end{tabular}

Standard errors in parentheses. $* * * \mathrm{p}<0.01, * * \mathrm{p}<0.05, * \mathrm{p}<0.1$

Table OA2. Performance change skipping rope.

\begin{tabular}{lccc}
\hline \hline VARIABLES & No controls & Set 1 & Set 2 \\
& $(1)$ & $(2)$ & $(3)$ \\
\hline Sweden & 6.541 & 8.020 & $8.854^{*}$ \\
& $(4.203)$ & $(5.132)$ & $(5.245)$ \\
Female & 1.794 & 7.203 & 7.321 \\
& $(4.130)$ & $(5.194)$ & $(5.322)$ \\
Female*Sweden & 3.769 & $14.70 * *$ & $13.28^{*}$ \\
& $(6.125)$ & $(7.350)$ & $(7.559)$ \\
Individual performance & & $-0.387^{* * *}$ & $-0.389^{* * *}$ \\
& & $(0.0423)$ & $(0.0423)$ \\
Age & & 2.246 & 1.742
\end{tabular}


Risk

Importance winning female

opponent

Skipping gendered

\begin{tabular}{lccc}
\hline Observations & 583 & 400 & 394 \\
R-squared & 0.016 & 0.193 & 0.197 \\
\hline \hline
\end{tabular}

Standard errors in parentheses. $* * * \mathrm{p}<0.01, * * \mathrm{p}<0.05, * \mathrm{p}<0.1$

Table OA3. Comparing the gender gap in performance change in running and skipping rope in Colombia.

\begin{tabular}{|c|c|c|c|}
\hline VARIABLES & $\begin{array}{l}\text { No controls } \\
\text { (1) }\end{array}$ & $\begin{array}{l}\text { Set } 1 \\
(2)\end{array}$ & $\begin{array}{l}\text { Set } 2 \\
(3)\end{array}$ \\
\hline Female & $\begin{array}{l}-0.420 \\
(0.360)\end{array}$ & $\begin{array}{l}-1.504 * \\
(0.887)\end{array}$ & $\begin{array}{l}-1.421 \\
(0.883)\end{array}$ \\
\hline Running & $\begin{array}{c}0.639 * * * \\
(0.177)\end{array}$ & $\begin{array}{c}0.377 * * \\
(0.151)\end{array}$ & $\begin{array}{c}0.374 * * \\
(0.151)\end{array}$ \\
\hline Female*Running & $\begin{array}{c}0.402 \\
(0.359)\end{array}$ & $\begin{array}{l}1.526^{*} \\
(0.841)\end{array}$ & $\begin{array}{l}1.474^{*} \\
(0.881)\end{array}$ \\
\hline Individual performance running & & $\begin{array}{c}0.0280 \\
(0.0422)\end{array}$ & $\begin{array}{c}0.0503 \\
(0.0547)\end{array}$ \\
\hline Individual performance skipping & & $-0.0176 * *$ & $-0.0170 * *$ \\
\hline & & $(0.00787)$ & $(0.00792)$ \\
\hline Age & & $\begin{array}{c}0.265^{*} \\
(0.139)\end{array}$ & $\begin{array}{c}0.203 * \\
(0.112)\end{array}$ \\
\hline Risk & & $\begin{array}{l}-0.0416 \\
(0.0377)\end{array}$ & $\begin{array}{l}-0.0467 \\
(0.0325)\end{array}$ \\
\hline $\begin{array}{l}\text { Importance winning female } \\
\text { opponent }\end{array}$ & & & $\begin{array}{c}0.0266 \\
(0.0610)\end{array}$ \\
\hline $\begin{array}{l}\text { Importance winning male } \\
\text { opponent }\end{array}$ & & & $\begin{array}{c}0.0123 \\
(0.0346)\end{array}$ \\
\hline Skipping gendered & & & $\begin{array}{c}0.0735 \\
(0.0783)\end{array}$ \\
\hline Running gendered & & & $\begin{array}{l}0.00735 \\
(0.0400)\end{array}$ \\
\hline Constant & $\begin{array}{c}-0.667 * * * \\
(0.177)\end{array}$ & $\begin{array}{l}-3.167 * \\
(1.623)\end{array}$ & $\begin{array}{c}-3.371^{*} \\
(1.720)\end{array}$ \\
\hline
\end{tabular}




\begin{tabular}{lccc}
\hline Observations & 655 & 213 & 211 \\
R-squared & 0.042 & 0.108 & 0.111 \\
\hline \hline
\end{tabular}

Standard errors in parentheses. $* * * \mathrm{p}<0.01,{ }^{*} \mathrm{p}<0.05,{ }^{*} \mathrm{p}<0.1$

Table OA4. Comparing the gender gap in performance change in running and skipping rope in Sweden.

\begin{tabular}{|c|c|c|c|}
\hline VARIABLES & $\begin{array}{c}\text { No controls } \\
\text { (1) }\end{array}$ & $\begin{array}{l}\text { Set } 1 \\
(2)\end{array}$ & $\begin{array}{c}\text { Set } 2 \\
(3)\end{array}$ \\
\hline Female & $\begin{array}{l}-0.118 \\
(0.382)\end{array}$ & $\begin{array}{l}0.170 \\
(0.543)\end{array}$ & $\begin{array}{c}0.262 \\
(0.564)\end{array}$ \\
\hline Running & $\begin{array}{l}0.928 * * * \\
(0.310)\end{array}$ & $\begin{array}{c}0.994 * * \\
(0.445)\end{array}$ & $\begin{array}{l}1.013 * * \\
(0.449)\end{array}$ \\
\hline Female*Running & $\begin{array}{c}0.116 \\
(0.381)\end{array}$ & $\begin{array}{c}0.118 \\
(0.519)\end{array}$ & $\begin{array}{r}-0.0340 \\
(0.511)\end{array}$ \\
\hline $\begin{array}{l}\text { Individual performance skipping } \\
\text { rope }\end{array}$ & & $\begin{array}{c}0.156 \\
(0.199)\end{array}$ & $\begin{array}{c}0.134 \\
(0.197)\end{array}$ \\
\hline Individual performance running & & $\begin{array}{c}-0.00498 * * * \\
(0.00136)\end{array}$ & $\begin{array}{c}-0.00494 * * * \\
(0.00131)\end{array}$ \\
\hline Age & & $\begin{array}{c}0.320^{* *} \\
(0.137)\end{array}$ & $\begin{array}{c}0.237 * * \\
(0.116)\end{array}$ \\
\hline Risk & & $\begin{array}{c}0.122 \\
(0.100)\end{array}$ & $\begin{array}{c}0.120 \\
(0.112)\end{array}$ \\
\hline $\begin{array}{l}\text { Importance winning female } \\
\text { opponent }\end{array}$ & & & $\begin{array}{c}0.0205 \\
(0.0281)\end{array}$ \\
\hline $\begin{array}{l}\text { Importance winning male } \\
\text { opponent }\end{array}$ & & & $\begin{array}{c}0.0103 \\
(0.0325)\end{array}$ \\
\hline Skipping gendered & & & $\begin{array}{c}0.0168 \\
(0.0487)\end{array}$ \\
\hline Running gendered & & & $\begin{array}{l}-0.0886 \\
(0.0658)\end{array}$ \\
\hline Constant & $\begin{array}{c}-0.960 * * * \\
(0.310)\end{array}$ & $\begin{array}{l}-7.433 \\
(4.995)\end{array}$ & $\begin{array}{l}-5.850 \\
(4.828)\end{array}$ \\
\hline Observations & 537 & 355 & 349 \\
\hline R-squared & 0.053 & 0.092 & 0.084 \\
\hline
\end{tabular}

Standard errors in parentheses. $* * * \mathrm{p}<0.01, * * \mathrm{p}<0.05,{ }^{*} \mathrm{p}<0.1$

Table OA5. Performance change math and word search, control variables set 1 .

\begin{tabular}{lccc}
\hline \hline VARIABLES & All & Math & Word \\
& $(1)$ & $(2)$ & $(3)$ \\
\hline
\end{tabular}




\begin{tabular}{lccc} 
Sweden & $0.901 * *$ & 0.704 & $1.313 * * *$ \\
Female & $(0.371)$ & $(0.571)$ & $(0.489)$ \\
& 0.143 & 0.0379 & 0.170 \\
Female*Sweden & $(0.381)$ & $(0.621)$ & $(0.471)$ \\
& 0.597 & 0.824 & 0.668 \\
Individual performance & $(0.494)$ & $(0.781)$ & $(0.631)$ \\
& $-0.389 * * *$ & $-0.355 * * *$ & $-0.477 * * *$ \\
Math & $(0.0251)$ & $(0.0348)$ & $(0.0431)$ \\
& $1.162 * * *$ & & \\
Age & $(0.252)$ & & $0.647 * * *$ \\
& $0.504 * * *$ & $0.517 * *$ & $(0.177)$ \\
Risk & $(0.139)$ & $(0.233)$ & 0.0437 \\
& 0.0531 & 0.0681 & $(0.0752)$ \\
Expected performance & $(0.0593)$ & $(0.0937)$ & $1.654 * *$ \\
& $2.117 * * *$ & $2.537 * * *$ & $(0.667)$ \\
\hline Observations & $(0.514)$ & $(0.792)$ & 391 \\
R-squared & 763 & 372 & 0.263 \\
\hline \hline
\end{tabular}

Standard errors in parentheses. $* * * \mathrm{p}<0.01, * * \mathrm{p}<0.05, * \mathrm{p}<0.1$

Table OA6. Performance change math and word search, control variables set 2 .

\begin{tabular}{lccc}
\hline \hline VARIABLES & All & Math & Word \\
& $(1)$ & $(2)$ & $(3)$ \\
\hline Sweden & $0.815^{* *}$ & 0.454 & $1.227^{* *}$ \\
Female & $(0.389)$ & $(0.619)$ & $(0.494)$ \\
& 0.0287 & -0.321 & 0.264 \\
Female*Sweden & $(0.409)$ & $(0.678)$ & $(0.497)$ \\
& 0.693 & 1.317 & 0.453 \\
Individual performance & $(0.521)$ & $(0.838)$ & $(0.661)$ \\
& $-0.385^{* * *}$ & $-0.340^{* * *}$ & $-0.470^{* * *}$ \\
Math & $(0.0254)$ & $(0.0358)$ & $(0.0428)$ \\
& $1.186^{* * *}$ & & \\
Age & $(0.254)$ & & \\
Risk & $0.485^{* * *}$ & $0.525^{* *}$ & $0.599^{* * *}$ \\
& $(0.140)$ & $(0.240)$ & $(0.177)$ \\
Expected performance & 0.0519 & 0.105 & 0.0296 \\
& $(0.0604)$ & $(0.0974)$ & $(0.0749)$ \\
Importance winning female & $2.069^{* * *}$ & $2.454^{* * *}$ & $1.608^{* *}$ \\
& $(0.517)$ & $(0.804)$ & $(0.663)$ \\
& -0.0272 & 0.0672 & $-0.0946^{*}$
\end{tabular}




$\begin{array}{lccc} & (0.0392) & (0.0647) & (0.0485) \\ \text { Importance winning male } & 0.0185 & 0.0294 & -0.00736 \\ \text { opponent } & (0.0395) & (0.0666) & (0.0475) \\ & -0.0569 & -0.0695 & -0.0603 \\ \text { Word gendered } & (0.0698) & (0.114) & (0.0854) \\ & -0.0223 & -0.107 & 0.0244 \\ \text { Math gendered } & (0.0710) & (0.120) & (0.0848) \\ & 749 & 362 & 387 \\ \text { Observations } & 0.271 & 0.290 & 0.276 \\ \text { R-squared } & & & \end{array}$

Standard errors in parentheses. $* * * \mathrm{p}<0.01, * * \mathrm{p}<0.05, * \mathrm{p}<0.1$

Table OA7. Comparing the gender gap in performance change in math and word search in Colombia.

\begin{tabular}{|c|c|c|c|}
\hline VARIABLES & $\begin{array}{c}(1) \\
\text { No controls }\end{array}$ & $\begin{array}{c}(2) \\
\text { Set } 1 \\
\end{array}$ & $\begin{array}{c}(3) \\
\text { Set } 2\end{array}$ \\
\hline Female & $\begin{array}{l}-0.185 \\
(0.427)\end{array}$ & $\begin{array}{c}0.188 \\
(0.482)\end{array}$ & $\begin{array}{c}0.231 \\
(0.512)\end{array}$ \\
\hline Math & $\begin{array}{c}-0.863 * * \\
(0.411)\end{array}$ & $\begin{array}{c}1.762 * * * \\
(0.510)\end{array}$ & $\begin{array}{c}1.784 * * * \\
(0.520)\end{array}$ \\
\hline Female*Math & $\begin{array}{c}0.557 \\
(0.603)\end{array}$ & $\begin{array}{c}-0.00626 \\
(0.706)\end{array}$ & $\begin{array}{c}-0.142 \\
(0.726)\end{array}$ \\
\hline Individual performance & & $\begin{array}{c}-0.551 * * * \\
(0.0419)\end{array}$ & $\begin{array}{c}-0.546 * * * \\
(0.0431)\end{array}$ \\
\hline Expected performance & & $\begin{array}{l}1.335^{*} \\
(0.707)\end{array}$ & $\begin{array}{l}1.296 * \\
(0.723)\end{array}$ \\
\hline Age & & $\begin{array}{l}0.365^{*} \\
(0.192)\end{array}$ & $\begin{array}{l}0.360^{*} \\
(0.198)\end{array}$ \\
\hline Risk & & $\begin{array}{c}0.0614 \\
(0.0673)\end{array}$ & $\begin{array}{c}0.0718 \\
(0.0689)\end{array}$ \\
\hline Importance winning female opponent & & & $\begin{array}{l}-0.0262 \\
(0.0496)\end{array}$ \\
\hline Importance winning male opponent & & & $\begin{array}{c}0.0357 \\
(0.0499)\end{array}$ \\
\hline Word gendered & & & $\begin{array}{l}-0.0319 \\
(0.0862)\end{array}$ \\
\hline Math gendered & & & $\begin{array}{r}-0.00917 \\
(0.0867)\end{array}$ \\
\hline Observations & 567 & 327 & 320 \\
\hline R-squared & 0.009 & 0.365 & 0.361 \\
\hline
\end{tabular}

Standard errors in parentheses*** $\mathrm{p}<0.01, * * \mathrm{p}<0.05, * \mathrm{p}<0.1$

Table OA8. Comparing the gender gap in performance change in math and word search in Sweden.

\begin{tabular}{lccc}
\hline \hline VARIABLES & $(1)$ & $(2)$ & $(3)$ \\
Female & No controls & Set 1 & Set 2 \\
\hline
\end{tabular}




\begin{tabular}{|c|c|c|c|}
\hline & $(0.467)$ & $(0.472)$ & $(0.492)$ \\
\hline \multirow[t]{2}{*}{ Math } & -0.168 & $0.956^{* *}$ & $1.064 * *$ \\
\hline & $(0.468)$ & $(0.471)$ & $(0.477)$ \\
\hline \multirow[t]{2}{*}{ Female*Math } & 0.905 & 0.240 & 0.162 \\
\hline & $(0.661)$ & $(0.671)$ & $(0.677)$ \\
\hline \multirow[t]{2}{*}{ Individual performance } & & $-0.314 * * *$ & $-0.313 * * *$ \\
\hline & & $(0.0321)$ & $(0.0326)$ \\
\hline \multirow[t]{2}{*}{ Expected performance } & & $2.552 * * *$ & $2.533 * * *$ \\
\hline & & $(0.732)$ & $(0.738)$ \\
\hline \multirow[t]{2}{*}{ Age } & & $0.662 * * *$ & $0.650 * * *$ \\
\hline & & $(0.198)$ & $(0.201)$ \\
\hline \multirow[t]{2}{*}{ Risk } & & -0.0196 & -0.0544 \\
\hline & & $(0.112)$ & $(0.114)$ \\
\hline \multirow{2}{*}{$\begin{array}{l}\text { Importance winning female } \\
\text { opponent }\end{array}$} & & & -0.0102 \\
\hline & & & $(0.0703)$ \\
\hline \multirow{2}{*}{$\begin{array}{l}\text { Importance winning male } \\
\text { opponent }\end{array}$} & & & -0.00555 \\
\hline & & & $(0.0704)$ \\
\hline \multirow[t]{2}{*}{ Word gendered } & & & -0.0744 \\
\hline & & & $(0.113)$ \\
\hline Math gendered & & & $\begin{array}{c}-0.00305 \\
(0.123)\end{array}$ \\
\hline Observations & 579 & 436 & 429 \\
\hline R-squared & 0.014 & 0.237 & 0.238 \\
\hline
\end{tabular}

Standard errors in parentheses $* * * \mathrm{p}<0.01, * * \mathrm{p}<0.05, * \mathrm{p}<0.1$

Table OA9. Competition choice math and word search, control variables set 1 .

\begin{tabular}{lccc}
\hline \hline \multirow{2}{*}{ VARIABLES } & $(1)$ & $(2)$ & $(3)$ \\
Sweden & All & Math & Word \\
& $0.639^{* *}$ & 0.105 & $1.359^{* * *}$ \\
Female & $(0.250)$ & $(0.343)$ & $(0.398)$ \\
& 0.145 & -0.218 & 0.612 \\
Female*Sweden & $(0.267)$ & $(0.386)$ & $(0.391)$ \\
& $-1.065^{* * *}$ & -0.819 & $-1.368 * * *$ \\
Individual performance & $(0.345)$ & $(0.498)$ & $(0.499)$ \\
& 0.0193 & 0.0254 & -0.00894 \\
Math & $(0.0170)$ & $(0.0212)$ & $(0.0351)$ \\
& 0.197 & & \\
Age & $(0.174)$ & & -0.109 \\
& -0.119 & -0.0783 & $(0.140)$ \\
Risk & $(0.0972)$ & $(0.148)$ & $0.117 * *$ \\
& $0.180^{* * *}$ & $0.239 * * *$ & $(0.0568)$ \\
Expected performance & $(0.0402)$ & $(0.0597)$ & $2.014 * * *$ \\
& $1.977 * * *$ & $2.104 * * *$ & $(0.559)$ \\
\hline Observations & $(0.381)$ & $(0.540)$ & 391 \\
\hline \hline
\end{tabular}

Standard errors in parentheses $* * * \mathrm{p}<0.01, * * \mathrm{p}<0.05, * \mathrm{p}<0.1$

Table OA10. Competition choice math and word search, control variables set 2.

\begin{tabular}{llll}
\hline \hline VARIABLES & Mll Word
\end{tabular}


(1)

\begin{tabular}{|c|c|c|c|}
\hline & & (2) & \\
\hline \multirow[t]{2}{*}{ Sweden } & $0.707 * * *$ & 0.159 & $1.376 * * *$ \\
\hline & $(0.267)$ & $(0.375)$ & $(0.410)$ \\
\hline \multirow[t]{2}{*}{ Female } & 0.263 & -0.121 & $0.682 *$ \\
\hline & $(0.287)$ & $(0.424)$ & $(0.414)$ \\
\hline \multirow[t]{2}{*}{ Female*Sweden } & $-1.127 * * *$ & -0.864 & $-1.377 * * *$ \\
\hline & $(0.364)$ & $(0.531)$ & $(0.530)$ \\
\hline \multirow[t]{2}{*}{ Individual performance } & 0.0186 & 0.0256 & -0.00939 \\
\hline & $(0.0172)$ & $(0.0217)$ & $(0.0354)$ \\
\hline \multirow[t]{2}{*}{ Math } & 0.235 & & \\
\hline & $(0.176)$ & & \\
\hline \multirow[t]{2}{*}{ Age } & -0.114 & -0.0581 & -0.120 \\
\hline & $(0.0981)$ & $(0.152)$ & $(0.142)$ \\
\hline \multirow[t]{2}{*}{ Risk } & $0.184 * * *$ & $0.254 * * *$ & $0.115^{* *}$ \\
\hline & $(0.0412)$ & $(0.0628)$ & $(0.0576)$ \\
\hline \multirow[t]{2}{*}{ Expected performance } & $1.970 * * *$ & $2.152 * * *$ & $1.969 * * *$ \\
\hline & $(0.385)$ & $(0.549)$ & $(0.563)$ \\
\hline \multirow{2}{*}{$\begin{array}{l}\text { Importance winning female } \\
\text { opponent }\end{array}$} & -0.0136 & -0.0160 & -0.00388 \\
\hline & $(0.0269)$ & $(0.0409)$ & $(0.0377)$ \\
\hline \multirow{2}{*}{$\begin{array}{l}\text { Importance winning male } \\
\text { opponent }\end{array}$} & 0.0440 & 0.0427 & 0.0383 \\
\hline & $(0.0277)$ & $(0.0426)$ & $(0.0375)$ \\
\hline \multirow[t]{2}{*}{ Word gendered } & 0.0434 & 0.0420 & 0.0353 \\
\hline & $(0.0485)$ & $(0.0739)$ & $(0.0660)$ \\
\hline \multirow[t]{2}{*}{ Math gendered } & -0.0250 & -0.0161 & -0.0430 \\
\hline & $(0.0495)$ & $(0.0788)$ & $(0.0651)$ \\
\hline Observations & 748 & 361 & 387 \\
\hline R-squared & 0.098 & 0.145 & 0.068 \\
\hline
\end{tabular}

Standard errors in parentheses. $* * * \mathrm{p}<0.01,{ }^{*} * \mathrm{p}<0.05, * \mathrm{p}<0.1$

Table OA11. Comparing the gender gap in choice in math and word search in Colombia.

\begin{tabular}{lccc}
\hline \hline VARIABLES & No controls & Set 1 & Set 2 \\
& $(1)$ & $(2)$ & $(3)$ \\
\hline Female & 0.0274 & 0.0853 & 0.102 \\
& $(0.0553)$ & $(0.0671)$ & $(0.0714)$ \\
Math & 0.0841 & $0.226^{* * *}$ & $0.234^{* * *}$ \\
& $(0.0533)$ & $(0.0713)$ & $(0.0728)$ \\
Female*Math & -0.0533 & $-0.189^{*}$ & $-0.207^{* *}$ \\
& $(0.0783)$ & $(0.0987)$ & $(0.101)$ \\
Individual performance & & 0.000838 & 0.00185 \\
& & $(0.00587)$ & $(0.00602)$ \\
Expected performance & & $0.173^{*}$ & $0.196^{*}$ \\
& & $(0.0981)$ & $(0.100)$ \\
Age & & -0.0419 & -0.0444
\end{tabular}




\begin{tabular}{lcc} 
& $(0.0267)$ & $(0.0276)$ \\
Risk & 0.0118 & 0.0120 \\
& $(0.00935)$ & $(0.00957)$ \\
Importance winning female & & -0.00695 \\
opponent & & $(0.00689)$ \\
Importance winning male & & -0.00217 \\
opponent & & $(0.00702)$ \\
Word gendered & & -0.000536 \\
& & $(0.0120)$ \\
Math gendered & & 0.00209 \\
& & $(0.0121)$ \\
\hline Observations & 560 & 320 \\
R-squared & 0.005 & 0.069 \\
\hline \hline
\end{tabular}

Standard errors in parentheses. $* * * \mathrm{p}<0.01, * * \mathrm{p}<0.05, * \mathrm{p}<0.1$

Table OA12. Comparing the gender gap in choice in math and word search in Sweden.

\begin{tabular}{lccc}
\hline \hline VARIABLES & No controls & Set 1 & Set 2 \\
& $(1)$ & $(2)$ & $(3)$ \\
\hline Female & $-0.114^{* *}$ & $-0.143^{* *}$ & $-0.114^{*}$ \\
Math & $(0.0540)$ & $(0.0583)$ & $(0.0606)$ \\
& 0.0577 & -0.00212 & 0.0154 \\
Female*Math & $(0.0540)$ & $(0.0582)$ & $(0.0587)$ \\
& $-0.140^{*}$ & -0.0283 & -0.0368 \\
Individual performance & $(0.0764)$ & $(0.0828)$ & $(0.0832)$ \\
& & 0.00317 & 0.00292 \\
Expected performance & & $(0.00396)$ & $(0.00400)$ \\
& & $0.515^{* * *}$ & $0.492^{* * *}$ \\
Age & & $(0.0901)$ & $(0.0906)$ \\
& & -0.0250 & -0.0281 \\
Risk & & $(0.0244)$ & $(0.0247)$ \\
Importance winning female & $0.0813^{* * *}$ & $0.0841^{* * *}$ \\
opponent & & $(0.0138)$ & $(0.0139)$ \\
Importance winning male & & -0.00231 \\
Word gendered & & & $(0.00863)$ \\
& & & $0.0171^{* *}$ \\
& & & $(0.00864)$ \\
& & & 0.0195 \\
& & &
\end{tabular}


(0.0139)

Math gendered

$-0.00176$

$(0.0151)$

Observations

576

435

428

R-squared

0.045

0.197

0.208

Standard errors in parentheses. $* * * \mathrm{p}<0.01,{ }^{* *} \mathrm{p}<0.05, * \mathrm{p}<0.1$ 